climatology of South Germany appears in the "Bavarian Meteorological Year-book" for Igog, viz. investigations by MM. E. Alt and L. Weickmann on thunderstorms and hail, from observations made in Bavaria, Württemberg, and Baden during $18_{93-1907}$ at carefully selected stations. The discussion is carried out in great detail, with tables for geographical districts, isopleths for thunderstorm frequency in W.-E. and N.-S. directions, and by charts, but we can only refer to some of the more general results. The mean daily period of thunderstorm frequency for the whole of South Germany shows that the principal maximum occurs between $2 \mathrm{~h}$. and $5 \mathrm{~h}$. p.m., 39 per cent. of storms taking place about $3 \mathrm{~h}$. p.m. In the annual period the storms occur most frequently between April and September, the maxima being in June and July. With regard to hailstorm frequency, 70 per cent. of the storms occur between noon and $6 \mathrm{~h}$. p.m., the maxima being from $3 \mathrm{~h}$. to $5 \mathrm{~h}$. p.m. In the yearly period they occur most frequently between May and July, the maximum being in June, and, compared with the number of thunderstorms, hailstorms were comparatively rare. It may be mentioned that investigations as to a possible connection of thunderstorm frequency with the sun-spot period led to no result.

The results of the meteorological and magnetical observations for 1909 at Stonyhurst College Observatory, Lancashire, have been received. The tables are, as usual, plainly arranged, and the departures from very long averages being given render the data exceedingly valuable. The weather of the year was generally mild and quiet: the temperature of June was $3.2^{\circ}$ below the average, and July and December were very wet, each having more than 4 inches above the average rainfall. The mean of the highest daily temperatures was $52 \cdot 1^{\circ}$, of the lowest $40.6^{\circ}$; adopted yearly mean, $46.2^{\circ}$ ( $0.6^{\circ}$ below the average for the last sixty-two years). The highest reading was $75.1^{\circ}$ (August 15), the lowest $15.1^{\circ}$ (December $2 \mathrm{I}$ ). The total rainfall was 48.77 inches ( 1.84 inches above the normal). The mean disc area of sun-spots (in units of I/500oth of the visible surface) appears at 3.8 , and the mean daily range of magnetic declination at $13.5^{\prime}$; the mean for the year was $17^{\circ} 28.5^{\prime} \mathrm{W}$. Photographic copies of noteworthy seismographs were supplied to various authorities, and would be sent to any observing station on application.

\section{THE PROGRESS OF AGRICULTURE IN}

\section{INDIA.}

I' would be difficult to conceive a harder task than that set before the members of the staff of the Agricultura Department of India when they first set to work to improve Indian agriculture. The native methods of working were often primitive, their seeds were impure and their crops uncertain; the ryots were uneducated, poor, and without that ambition to rise that would have gone so far to lighten the work of the newcomers; but, in spite of all this, the Department has, in the space of a comparatively few years, done a vast amount of work; it has to chronicle failures as well as successes, but the successes have largely preponderated, and we can see some of the results in the various reports that have recently been issued.

The research institute for the Indian Empire is at Pusa, an estate of more than 1300 acres bounded on three sides by a loop of the little Gundak River. It is situated in the heart of a district where intensive cultivation prevails in consequence of the favourable climatic and soil conditions, which are also indicated by the density of the population-900 to r 100 per square mile. As, moreover, the district is largely controlled by a community of indigo planters, there is little fear that cultural improvements suggested by the staff should be unnoticed. The Phipps laboratory is said to be admirably suited for its purpose; it is provided with water-power and electricity, while the

1 Report on the Progress of Agriculture in India for 1907-g. (Calcutta : Superintendent Governmert Printing, India.

Report on the Introduction of Improvements into Indian Agriculture by the Work of the Agricultural Departments.

Report of the Agricultural Research Institute and College, Pusa, :907-9.

Agricultural Statistics of India for the Years 1903-4 to 1907-8. 2 vols. Report on the Operations of the Department of Agriculture, Madras Presidency, for the Official Year rgo8-9.
Madras Agricultural Calendar, 910 .

NO. 2 I I6, VOL. 83] soil of the experimental grounds can be made to grow practically all the important crops of the plains. The scientific staff comprises an agriculturist, a botanist, a chemist, two entomologists and a mycologist, with their supernumeraries and assistants.

In the botanical department Mr. Howard's work on wheat promises results of considerable importance both to India and to Great Britain. He has completed the classification of the Punjab wheats and has isolated some twentyfive pure types, the best of which will in time be available for general distribution. A survey on similar lines of the varieties grown in the Central Provinces, Bengal, Bombay, the United Provinces and Burma is in hand. This work is being followed by hybridisation to evolve new varieties possessing strength of straw, good cropping power and resistance to rust. Some of the pure types which are being used as parents were found to be a great improvement on the mixed sorts previously grown, and we are not surprised to read that "large numbers of colonists came to see the plots and arranged for small supplies of seed for trial on their holdings." Not only is there the likelihood of an increased yield, but it appears that India can grow "strong" wheats such as are required in the English market, the common impression that Indian wheats are necessarily weak being erroneous. The economic results of a notable increase in wheat production of high quality can hardly be overestimated. An interesting physiological problem is also under investigation. It was found in 1908 that the same sample of Muzaffernaggar wheat sown at Lyallpur, Muzaffernaggar and Pusa gave rise to grain varying markedly in appearance, composition, milling and baking qualities. Mr. Shutt has observed similar variations in Canada. The cause can hardly lie in the amount of plant food in the soil, since no such variation is observed in going from plot to plot on the Broadbolk wheat field at Rothamsted; it must lie in some other of the factors constituting the general environment. Further investigations will be awaited with much interest.

Dr. Butler has continued the mycological work on the lines of previous years, very wisely concentrating attention on a few diseases, and carefully working out the life-history and general biology of the organisms involved. Of these, the chief are "red rot" in sugar-cane, the palm diseases, the wilt diseases of various crops, "white rust" and other diseases of citrus, the mulberry disease of Kashmir, and others. So successful has Dr. Butler been in combating the palm disease in the Godavari delta that he is considered on this work alone to have paid the cost of his department for many years to come! He has in preparation a book on Indian plant diseases that may be expected to help Indian planters considerably.

Dr. Leather was away on leave for part of the time, his place being taken by Mr. Annett. Work was continued on the losses of water from the soil, and the water requirements of plants, subjects that are obviously of fundamental importance in India. It was found also, in the first instance by pot experiments, and later bv field trials, that certain soils benefitted notably by manuring with phosphates.

The task of controlling the insect pests falls to the lot of Mr. Maxwell-Lefroy, the Imperial entomologist, and $\mathrm{Mr}$. Mason, with assistants for special work, but the staf is small for the work it has to do. The life-histories and habits of a number of iniurious insects have been investirated, and also the influence of climatic changes on insect life and the problem of utilising beneficial insects. Attention has been devoted to seri-culture and to lac. The second entomologist, $\mathrm{Mr}$. Howlett, investigates Diptera. $\mathrm{He}$ has ascertained the life-histories of nearly all the mosquitoes occurring at Pusa, and has, in addition, found two species of fish capable of destroying large numbers of Anopheles larvæ. The number of Diptera injurious to crops and animals is very considerable, and fully iustifies the appointment of an entomologist to deal especially with them.

The improvement of the livestock and poultry of India is undertaken by the Agricultural Department under the direction of $\mathrm{Mr}$. Shearer. A large and remunerative export trade in Indian cattle has recently arisen, for which the Montgomery appears especially suitable. Careful attention is therefore being devoted to this breed.

Such is a brief outline of the main lines of work at 
Pusa. The various provinces have also agricultural departments, with scientific staffs investigating problems of local importance and methods suitable for their own districts; an example of the kind of work they do is afforded by a study of the Madras report. The methods of bringing the scientific work to the notice of the cultivators were discussed by a committee of the Board of Agriculture and collected in their report-the second on our list. Whilst they vary somewhat in the different provinces, they may be classed roughly as (I) agricultural associations; (2) local demonstrations; (3) village agencies which hire out improved implements and demonstrate their use ; (4) vernacular journals controlled by the Department, those run by private enterprise not being always satisfactory; (5) leaflets, circulars, and communiques to the Press; (6) shows; (7) itinerant assistants, who, under suitable conditions and when working on one definite problem, have been found of considerable service; (8) seed farms and depots to do the work which seed merchants do here; (9) schools to train the sons of cultivators (10) colonisation with expert cultivators. Like the cultivator of the soil in all countries, the ryot is conservative but not unwilling to take up a new thing that is clearly going to be of advantage; he suffers, however, sorely from lack of funds, and we are told that he often has to pay so much as 24 per cent. interest or more per annum for the money which he must borrow if he is to effect improvements. He must therefore get more than 24 per cent. return or he loses on the transaction, and so it may happen that an improvement which would be profitable elsewhere is of no advantage to him. This state of affairs can only slowly be remedied, and must for long remain a bar to the general improvement of Indian agriculture.

But when we turn to the large cultivators there is no such hindrance, and it may reasonably be expected that they will gain considerable benefit from the scientific work that is being done. To give only one instance, $\mathrm{Mr}$. Bergtheil is investigating the problems of the indigo planters, and has already obtained results of value, 3 number of improvements having been effected of notable aggregate value. It has been shown, further, that the yield per acre can be increased very considerably by substituting the Java for the more common Sumatrana variety. By selection and hybridisation it may be possible to get even better results. The belief is expressed in the report that the natural indigo will yet compete successfuily with the synthetic product.

Such large works as irrigation are outside the scope of the present reports, although of great importance to the advancement of agriculture. Work is, however, in hand on the reclamation of reh or alkali land, a condition that may accompany irrigation unless drainage is also attended to. Mr. Henderson is making satisfactory progress in reclaiming the very salt soils of Sind. Other important improvements are going on, and we may in the near future look for great returns for the work that is now being done.

E. J. R.

\section{THE MESSINA EARTHOUAKE AND ITS PREDECESSORS.}

I TALIAN Government Commissions have recently issued two valuable reports on the earthquakes of Calabria and Messina. One of them deals with the earthquake of November I6, 1894, a shock of great interest, but overshadowed by the disasters of 1905 and 1908 . The greater part of this report, of 350 quarto pages, consists of a detailed account of the earthquake by Prof. A. Ricco. Sig. E. Camerana considers the nature and distribution of the damage to property, and suggests methods of construction that should be employed in future; Dr. M. Baratta investigates the relations of the earthquake with its predecessors; and Dr. G. di-Stefano describes the geological structure of the district. The epicentral area includes the villages of San Procopio, Santa Eufemia, and Seminara, which lie near the west coast of Calabria and about twenty miles from Messina and Reggio. The number of persons killed at these and other places was Ior, and the number of wounded about a thousand, the highest death-rate, of about 5 per cent., occurring at San Procopio. The epicentre coincides nearly with that of the well-known Calabrian earthquake of February 5, I783. The isoseismal lines of the two earthquakes were similar in form, both being flattened and compressed towards the east, and expanding in the opposite direction. The earthquake of ${ }_{17} \delta_{3}$ was, however, much the stronger, the loss of life far greater (the death-rate at one place rising to 75 per cent.), and the after-shocks were five times as numerous as in 1894, were of greater intensity, and were spread over a longer interval of time. The earthquake of 1894 was, in fact, a replica, on a much smaller scale, of the greatest of all Calabrian earthquakes.

The Messina earthquake of $x g 08$ is of far greater interest and importance than its predecessor of 1894 , and it is satisfactory to find that the reports on it are being issued without undue loss of time. A Royal Commission, under the presidency of Prof. Blaserna, was appointed to investigate the sites best adapted for the re-building of the ruined towns. The report of the commission is of more than local value. As regards Messina, while recognising the unsatisfactory nature of the subsoil, it is realised that, for commercial and other reasons, the city must be re-built on its former site. It is recommended, however, that the building regulations adopted for districts of high seismicity should be rigorously enforced, and that no buildings intended as permanent dwellings should be erected on loose sands and gravels on sloping ground or within a hundred metres of the sea, and the commission also points out certain suburban districts in which the city might be allowed to expand.

'Two or three of the appendices to the report are of considerable interest. In one, Sig. P. Marzolo, director of the Hydrographic Institute, compares the results of the soundings recently made in the Straits of Messina with those made in $18,6-7$. There are, he finds, no abrupt changes of level, but outside the Straits, to the north, the bathymetric curves of 200 and 300 metres are now much farther from both the Sicilian and Calabrian shores than they were in 1877 , while the curve of 400 metres near the Calabrian coast no longer exists. Sig. Marzolo, however, refers the change to deposits from ocean currents rather than to elevation of the sea-bed. In the harbour of Messina, the bathymetric curves for the years 1903 and 1909 are practically coincident, and this is also nearly the case with the curves for 1908 and 1909 for the harbour of Reggio.

In another appendix Sig. A. Loperfido describes the results of new series of levellings, former series having been made along the same lines. in 1907-8. In each case the $n \in w$ levellings were begun at points so distant that their altitude may be regarded as unchanged by the earthquake. In Calabria they started at Gioia Tauro $(9 \mathrm{~km}$. north of Palmi), and were continued round the south coast over a length of $87 \mathrm{~km}$. The changes of level, at first inconspicuous, begin to exceed a tenth of a metre at Favazzina, and from this place to Saline they indicate a continuous lowering of the coast, amounting to $42 \mathrm{~cm}$. at Villa S. Giovanni and $54 \mathrm{~cm}$. at Reggio, with a maximum of $58 \mathrm{~cm}$. about a kilometre south of Reggio. In Sicily three shorter lines of levelling were carried out, one from Capo Peloro to Messina, and the others inland from the latter city. They show a lowering of $65 \mathrm{~cm}$. at the mareograph of Messina, a maximum of $71 \mathrm{~cm}$. being attained about 3 kilometres farther north.

A paper by Sig. F. Eredia on Messinese earthquakes has appeared in the Bollettino of the Italian Seismological Society (vol. xiii., pp. $48 \mathrm{r}-96$ ). In this he describes a series of earthquakes which occurred in August, 1898, the centres of which were near Rometta, which lies seven miles south-west of Messina. Two of these shocks (on August 6 and 12) were strong enough to cause slight damage to buildings at Rometta, and before the end of the month they were followed by at least eighty slighter tremors. The centres of both shocks were beneath the Peloritan mountains. Comparing the areas most strongly shaken by them with others disturbed in April, 1893, and Februarv, 1904, it would seem that, during the eleven years, there has been a continual northerly migration of the epicentres. 